\title{
DA CRIAÇÃO À CESSAÇÃO DAS ATIVIDADES ESCOLARES EM UMA ESCOLA PARA SURDOS: AVANÇOS E LIMITES DE UMA PROPOSTA
}

\author{
FROM THE CREATION TO THE END OF \\ ATICTIVITIES IN A SCHOOL FOR DEAF STUDENTS: \\ ADVANCES AND LIMITS OF A PROPOSAL
}

\section{Simone de Fátima Flach*}

\begin{abstract}
RESUMO
O texto objetiva apresentar análise parcial de dados de pesquisa sobre o período de existência de uma escola para o ensino de alunos surdos no município de Ponta Grossa - PR. Para tanto são analisados os documentos relativos à autorização e cessação das atividades escolares, proposta pedagógica, regimento escolar e relatórios anuais do período em que a escola funcionou (2001 -2008). A análise dos documentos demonstra o tênue limite entre o que se propõe e o que efetivamente se realiza em propostas educacionais ditas inovadoras, alertando para a necessidade de ampliar o debate sobre a inclusão de alunos com deficiência no ensino regular. Além disso, chama a atenção para a imprescindibilidade de eficiência e eficácia no atendimento especializado, seja no contexto da escola regular ou das instituições de atendimento educacional especializado. Ainda, indica a necessidade de aprofundamento sobre as questões político-educacionais do período para uma compreensão mais ampla dos efeitos das ações empreendidas.
\end{abstract}

Palavras-chave: Instituição Escolar. Escola para Surdos. História da Educação Municipal.

\begin{abstract}
This article aims to present a partial analysis of data from research on the lifetime of a school for deaf students in the city of Ponta Grossa - PR. For this, the documents related to the authorization and cessation of school activities, pedagogical proposals, school regulations and annual reports of the period in which the school functioned (2001 -2008) are analyzed. The analysis of the documents demonstrates the fine line between what is proposed and what actually takes place in the so-called innovative educational proposals, which may highlight the need to broaden the debate on the inclusion of students with special or different needs in mainstream schools. In addition, the article calls attention to the need for efficiency and effectiveness in specialized care in the context of regular schools or in institutions that offer specialized educational services. The article also highlights the need for further political and educational studies about that period aforementioned for a broader understanding of the effects of the actions taken.
\end{abstract}

Keywords: School. School for the deaf. History of municipal education.

\footnotetext{
* Docente do Departamento de Pedagogia da Universidade Estadual de Ponta Grossa; Doutora em Educação pela Universidade Federal de São Carlos UEPG; Pesquisadora vinculada ao Grupo de Pesquisa Capital, Trabalho, Estado e Educação: Políticas Educacionais e Formação de Professores - UEPG. E-mail: <eflach@uol.com.br>.
} 


\section{Introdução}

No presente texto pretende-se relatar parcialmente dados do projeto de pesquisa intitulado "Escolas Municipais em Ponta Grossa: determinantes na criação, existência político-pedagógica e cessação de atividades escolares", o qual se encontra em processo de desenvolvimento junto à Universidade Estadual de Ponta Grossa e tem, dentre outros objetivos, o de analisar os interesses e as influências no processo de criação, autorização e cessação de escolas a partir das determinações legais e normativas em diferentes períodos político-educacionais.

A pesquisa tem sido conduzida através de levantamento histórico sobre as escolas municipais em funcionamento no período 2001- 2011, da organização dos documentos da vida legal dos referidos estabelecimentos, bem como de análise de sua organização pedagógico-administrativa. A organização dos documentos da vida legal dos estabelecimentos de ensino tem sido realizada através de levantamento, catalogação e digitalização de fontes junto aos arquivos das Divisões de Estrutura e Funcionamento do Ensino e de Documentação Escolar da Secretaria Municipal de Educação de Ponta Grossa. A análise sobre a organização pedagógico-administrativa dos estabelecimentos tem sido realizada, em um primeiro momento, através de levantamento sobre a existência de projetos político-pedagógicos e, em um segundo momento, através da análise sobre tais documentos sob a luz do referencial materialista histórico e dialético, com o intuito de desvelar significados e interesses não explícitos na existência dessas instituições.

Durante o processo de coleta de dados e organização de fontes no contexto pesquisado - resoluções de autorização, de prorrogação e cessação de funcionamento de atividades escolares -, uma realidade específica destacou-se das demais. Essa realidade dizia respeito à existência de uma escola para o ensino de alunos surdos. No entanto, mesmo sendo um estabelecimento de ensino fundamental, supostamente com uma proposta inovadora de ensino bilíngue, a existência de tal escola foi efêmera, pois a mesma funcionou no período de $2001-2008$. Os interesses e as influências, tanto políticos quanto sociais e pedagógicos, envolvidos na existência de tal estabelecimento se mostraram importantes para a pesquisa em andamento, principalmente no que diz respeito aos compromissos dos governos responsáveis pela administração pública no período. Para tanto, procuramos levantar, através dos documentos disponíveis - processos de autorização de funcionamento, propostas pedagógicas, regimentos escolares e, enfim, o processo de cessação de funcionamento das atividades escolares - os interesses contidos na proposta que fundamentou sua autorização e que passados poucos anos se mostrou limitada a ponto de justificar o fim de seu funcionamento.

O levantamento apresentado demonstra o tênue limite entre o que se propõe e o que efetivamente se realiza em propostas educacionais ditas inovadoras, nos alertando para a necessidade de ampliar o debate sobre a inclusão de alunos com deficiência no ensino regular. Além disso, nos chama a atenção para a imprescindibilidade de eficiência e eficácia no atendimento especializado, seja no contexto da escola regular ou das instituições de atendimento educacional especializado. Ao que tudo indica, o debate sobre a questão do ensino de alunos surdos não se findou com a cessação das atividades escolares no estabelecimento em questão, visto que os alunos são cidadãos reais e, mesmo inseridos em escolas regulares, sob o manto da chamada inclusão educacional, seu atendimento não pode ser negligenciado. Acima da existência, ou não, de escolas ou instituições que ofereçam atendimento especializado, enquanto cidadãos os alunos precisam da aprendizagem escolar, sem a qual a escola regular deixa de cumprir sua função e os alunos deixam de usufruir um direito fundamental de cidadania.

Para além de uma análise dos interesses existentes em uma proposta educacional escolar, o presente texto se insere em um campo minado onde propostas divergentes de atendimento educacional para pessoas surdas não podem se situar apenas no campo da pesquisa acadêmica, ou serem ignoradas. É preciso considerar que as controvérsias e os conflitos sempre estiveram presentes na educação das pessoas "diferentes" do padrão considerado normal. Portanto, defende-se que para o desenvolvimento do indivíduo enquanto cidadão é imprescindível o domínio dos conhecimentos necessários não apenas para agir, mas para interferir no curso da atual sociedade. Sem tais conhecimentos, o indivíduo não pode 
ser considerado em sua plenitude, sendo fadado a continuar sendo considerado inferior aos demais, com menor capacidade de aprender e, consequentemente, vivendo marginalizado socialmente.

\section{Situando a educação de surdos}

Para as pessoas que pautam suas vidas, total ou parcialmente, no silêncio, viver em uma sociedade que funciona sob a perspectiva de uma comunidade de ouvintes não é tarefa fácil. A organização da atual sociedade capitalista valida a divisão dos seres humanos e coloca essa separação em situação de normalidade diante das exigências do capital, em um processo no qual uns são mais capazes do que outros, A situação do indivíduo surdo também se insere nessa lógica, visto que a chamada "anormalidade" gerada pela "surdez" nada mais é do que mais uma diferença que se mistura na engrenagem da sociedade e para a qual o capital não pode, ou não deve, preocupar-se, visto que outros indivíduos "normais" estão aptos para colaborarem na expansão capitalista desenfreada.

Os surdos sempre foram, historicamente, estigmatizados, considerados de menor valor social. Afinal, faltava-lhes a característica eminentemente humana: a linguagem (oral, bem entendido) e suas virtudes cognitivas. Sendo destituídos dessas "virtudes", os surdos eram "humanamente inferiores". [...]. A exclusão profissional e social dos surdos ainda hoje confirma que a linguagem pode ser fonte de discriminação e de organização social restritiva. Essa discriminação não ocorre apenas quando há diferenças de nacionalidade, cor, perfil socioeconômico ou religião. Entre os surdos e os ouvintes há uma grande diferença que os distingue: a linguagem oral. (SANTANA; BERGAMO, 2005, p. 565).

Nesse contexto, pensar em uma educação que ofereça aos indivíduos surdos os instrumentos necessários para agir, individual e coletivamente, e interferir no curso da sociedade é não apenas necessário, mas imprescindível. Principalmente quando se pensa em uma sociedade sem distinção de classes, em que todos os indivíduos devem viver, trabalhar e usufruir do ócio de forma igual. É nessa perspectiva que se insere o estudo ora relatado.

A educação de pessoas surdas nunca foi pacífica devido aos limites impostos pela dificuldade de comunicação entre ouvintes e surdos. Diferentes perspectivas teóricas existem e colocam o campo em constante conflito, pois as questões da linguagem se inserem no centro da discussão, deixando as questões educacionais em segundo plano.

É importante notar nessa história que, embora as discussões façam referência à educação, as questões próprias das esferas educacionais nunca foram enfatizadas. Os métodos de ensino, as práticas realizadas, assim como os conteúdos ensinados foram submetidos ao fator lingüístico e abordados com o objetivo de descrever e sustentar a defesa pelo desenvolvimento dessa ou daquela língua (oral ou de sinais). (LODI, 2005. p. 411).

Conforme a perspectiva defendida quanto ao desenvolvimento da linguagem do indivíduo surdo, a inserção dele no contexto educacional pode ocorrer em escolas comuns (em classes regulares ou especiais) ou em escolas especiais para surdos. No entanto, indo além da simples inserção do indivíduo no espaço escolar, a questão metodológica não é menos importante, visto que o desenvolvimento pedagógico pode ocorrer sob diferentes enfoques: oralismo, comunicação total, ou bilinguismo.

Em linhas gerais, o oralismo visa ao uso da linguagem oral como única possibilidade linguística, utilizando-se a voz e a leitura labial em todos os contextos, social e escolar. A comunicação total considera as características da pessoa surda e visa à utilização de qualquer recurso que possibilite e potencialize a comunicação, fazendo uso de textos orais, escritos, gestos e interações sociais. Importa ressaltar que tanto o oralismo quanto o enfoque pautado na comunicação total não consideram a língua natural das pessoas surdas.

O enfoque pautado no bilinguismo considera que, no contato com surdos adultos (usuários da língua e participantes ativos do processo educacional), as crianças surdas devem desenvolver a língua de sinais como primeira língua e, a partir dela, desenvolver a língua escrita, tendo a segunda língua (língua dos ouvintes) como base de estudos (LODI, 2005).

É importante ressaltar que a educação bilíngue é uma perspectiva bastante recente na realidade brasileira, visto que as experiências nesse enfoque são restritas e somente passaram a ser sistematizadas de forma mais efetiva a partir do Decreto 5.626/05, que regulamentou a utilização da 
Língua Brasileira de Sinais no contexto educacional. Essa regulamentação prevê a organização de turmas bilíngues, constituídas por alunos surdos e ouvintes, define a LIBRAS como primeira língua e, como segunda, a língua portuguesa na modalidade escrita. E, ainda, orienta a formação de professores e de intérpretes.

No entanto,

Em sua maioria, os surdos brasileiros desconhecem ou pouco conhecem a língua de sinais, buscam aprender o português como língua única, freqüentam escolas para ouvintes e, dadas as dificuldades de aprendizagem que apresentam, acabam por abandoná-las. Mesmo nas escolas especiais que dizem aceitar a língua de sinais, ainda são poucas as que permitem que professores surdos façam parte de seu corpo docente (como professores ou como instrutores). (LODI, 2005. p. 420).

O desafio de criar e manter uma escola para alunos surdos, organizada sob o enfoque de uma educação bilíngue, é deveras complexo. Todavia, uma escola precisa ser organizada administrativa e pedagogicamente para atingir os objetivos que propõe, sob pena de negligenciá-los e conduzir-se à inépcia de sua função. É essa questão que se pretende desvelar ao se expor a vida efêmera de uma proposta que poderia ter sido uma grande alavanca para o desenvolvimento da educação dos surdos no contexto pesquisado, mas que, segundo os resultados obtidos no período, se mostrou ineficaz e ineficiente ao ponto de justificar sua extinção.

\section{Avanços e limites de uma proposta educa- cional}

A educação de pessoas surdas no município de Ponta Grossa se insere de forma articulada com a história educacional dos surdos em um âmbito mais amplo, representando um movimento dialético singular em relação aos acontecimentos mais universais. A história educacional dos surdos em âmbito municipal vincula-se às determinações sociais, políticas, históricas gerais e locais e às defesas teóricas a respeito, conforme tendências e enfoques educacionais específicos para esse grupo específico de indivíduos. Dessa forma, o contexto pesquisado expressa uma realidade contraditória, sendo singular, particular e ao mesmo tempo geral e universal.
A Escola para Surdos em análise foi criada no ano de 2001, através do Decreto Municipal no 575, de 17/10/01, sendo autorizado o seu funcionamento no ano de 2002 através da Resolução Estadual $3.334 / 02$, de $09 / 09 / 02$. No momento inicial a referida escola funcionou junto a um Centro de Reabilitação Auditiva e da Fala, visto que esta instituição já desenvolvia o atendimento às pessoas surdas na região. Inclusive, pode-se afirmar que a Escola para Surdos teve, em muitos momentos, um conflito de identidade, pois além de funcionar no mesmo espaço físico do referido Centro, dele utilizou a denominação até o ano de 2003, quando recebeu denominação própria ${ }^{1}$. É preciso esclarecer que a criação da Escola para Surdos nos parece ter sido uma alternativa muito mais administrativa do que propriamente uma necessidade pedagógica, conforme justificativa apresentada pela Secretaria Municipal de Educação:

Houve a necessidade de, além do Processo de Autorização de Funcionamento do próprio Centro, da Criação e autorização da Escola Para Surdos Geny de Jesus S. Ribas, para regularizar a documentação escolar das crianças atendidas naquele local. Porque, além de prestar atendimento clínico, o CEPRAF, passou a cuidar, também da educação escolar das mesmas. (PONTA GROSSA. SME apud PARANÁ, 2003, p. 1) (grifos nossos).

A questão evidenciada na justificativa apresentada - "regularização da documentação escolar das crianças atendidas naquele local" - insere-se na discussão dicotômica de atendimento especializado em instituições próprias versus atendimento educacional especializado no ensino regular, evidenciando o não atendimento de pessoas surdas no contexto da educação regular, ou um atendimento deficiente que não consegue atender às necessidades educacionais de tais indivíduos. Historicamente, essa situação é reincidente no espaço do atendimento especializado em diferentes áreas, não sendo situação isolada para $\mathrm{o}$ atendimento de pessoas surdas.

No entanto, a denominação da Escola para Surdos necessitou ser alterada devido às exigências

\footnotetext{
1 A escola para surdos foi criada com a denominação de "Escola Municipal para Surdos Geny de Souza Ribas - Educação Infantil e Ensino Fundamental" e sua localização era a mesma do CEPRAF - Centro Pontagrossense de Reabilitação Auditiva e da Fala "Geny de Jesus Souza Ribas". Em 2003 a escola passou a denominar-se "Escola Municipal para Surdos Prof. Elisete Delgobo - Educação Infantil e Ensino Fundamental".
} 
legais referentes à documentação jurídica do estabelecimento. Essa alteração poderia ter contribuído para a superação do conflito de identidade existente entre a Escola para Surdos e o Centro de atendimento especializado.

\section{$[\ldots]$}

O primeiro impasse com relação ao nome da escola foi quando a Diretora da Escola precisou constituir a associação de pais e mestres do estabelecimento de ensino, para então registrar o CNPJ e, a partir deste, regularizar os demais papéis da Escola. Isso não foi possível naquele momento, visto que já havia um CNPJ com o mesmo nome da escola Geny, ou seja, o do CEPRAF. A alternativa, então, seria a mudança de denominação.

$[\ldots]$

Ainda, existe a questão do Convênio de Cooperação Técnica e Financeira firmado entre Estado e o Município/CEPRAF, o qual precisa ser regularizado e prorrogado. Conforme as orientações do Departamento de Educação Especial da SEED/ $\mathrm{PR}$, o Centro não poderia continuar recebendo a verba se não tivesse com a Escola autorizada e a APM devidamente constituída. (PONTA GROSSA. SME. apud PARANÁ, 2003, p. 1) (sem grifos no original).

O que ficou evidenciado nos documentos disponíveis foi que como o Centro de Atendimento já prestava atendimento escolar às pessoas surdas e não apenas o atendimento clínico, o conflito existente foi estabelecido antes mesmo da criação da Escola para Surdos. A criação da escola especializada, ao que tudo indica, configurou-se, então, como uma necessidade administrativa para "regularizar a documentação escolar atendida naquele local", visto que, provavelmente, não havia esse atendimento em uma instituição de educação formal.

A situação evidenciada no processo de criação da escola em questão não é rara na realidade brasileira, principalmente por serem inexistentes ou precárias as políticas educacionais voltadas àqueles que demandam atendimento especializado; ou, ainda, quando estas existem são de qualidade duvidosa para as reais necessidades da comunidade que utiliza a escola pública.

A criação da Escola para Surdos causou um entendimento conflituoso entre as funções específicas desenvolvidas no espaço dos atendimentos clínico e educacional, aquele oferecido pelo Centro e este pela Escola. É importante ressaltar que durante todo seu período de existência, mesmo após ter recebido outra denominação, a Escola para Surdos foi confundida com o Centro de Reabilitação Auditiva e da Fala.

Entretanto, a criação de uma escola para surdos, em 2001, pode ser considerada um avanço ao superar o atendimento clínico até então oferecido pelo Centro. A possibilidade de oferecimento de uma educação escolar para os indivíduos que se encontravam na idade respectiva e que não estavam devidamente matriculados no ensino regular pode ser considerada uma alternativa possível, visto que estavam excluídos do sistema educacional ou mesmo marginalizados dentro dele. Para esses indivíduos, as possibilidades de superação das desigualdades reproduzidas pelo sistema de ensino, quando inexiste oferta educacional de qualidade, podem ser oferecidas em espaço que agregue tanto o atendimento clínico quanto o pedagógico. Parece-nos que o grande trunfo da proposta de educação para surdos poderia estar inserido nessa organização até então inexistente.

No entanto, os surdos poderiam superar as desigualdades que a sociedade capitalista lhes impõe? A oferta educacional em uma escola para esse grupo específico poderia ser uma alternativa para essa superação? As respostas para essas questões estão vinculadas à forma de organização e encaminhamento pedagógico da escola, bem como aos processos e resultados da efetiva aprendizagem dos alunos. Em uma sociedade capitalista, aqueles que defendem sua superação não podem permitir que os alunos passem pela escola sem dominarem o mínimo de conhecimentos necessários para a vida em sociedade, para a compreensão crítica dessa sociedade. $\mathrm{O}$ entendimento das formas de exploração existentes e as possibilidades para a sua superação exigem conhecimentos específicos, os quais também são oferecidos pela educação escolar. Essa é uma questão que precisa ser pensada, mesmo nos limites do atendimento educacional especializado. Assim, a organização pedagógica e curricular para a garantia do aprendizado parece ser central em qualquer proposta que vise a ofertar uma educação de qualidade, que propicie aos surdos viver, trabalhar, usufruir os bens culturais disponíveis a todos, sem a formação de guetos ou comunidades marginalizadas. 
Por isso, é importante retratar a organização pedagógica e curricular da escola aqui analisada, visando a destacar de forma geral como ocorria o atendimento nessa instituição e a vinculação deste com o atendimento nas demais escolas regulares do município.

Segundo o Regimento Escolar, a referida escola oferecia "educação infantil ( 0 a 6 anos), ensino fundamental, I ciclo $=7$ e 8 anos; II ciclo=9, 10 e 11 anos; iniciação ao trabalho (a partir dos 14 anos) e Apoio Pedagógico (apoio pedagógico ao surdo com dificuldades de aprendizagem no ensino regular)" (REGIMENTO ESCOLAR, 2001, p. 2). Essa era a proposta inicial de escolarização de pessoas surdas no primeiro ano de funcionamento da Escola, a qual visava ao atendimento de alunos surdos no processo de escolarização inicial (educação infantil e anos iniciais do ensino fundamental), iniciação para o trabalho (sem previsão de como isso ocorria) e, ainda, apoio pedagógico para alunos regularmente matriculados no ensino regular.

No entanto, o Regimento Escolar do ano de 2002 apresenta uma importante modificação em relação à organização proposta inicial, vinculando-se à organização das demais escolas da Rede Municipal, as quais eram organizadas em ciclos de aprendizagem assim constituídos: $1^{\circ}$ ciclo, organizado com base na idade para crianças de 6, 7 e 8 anos, podendo ser um "continuum" de três anos de duração para os alunos que iniciavam a escolarização aos 6 anos e de dois anos de duração para aqueles que a iniciavam aos 7 anos; e $2^{\circ}$ ciclo como um "continuum" de dois anos de duração com base na estrutura seriada, correspondente à $3^{\mathrm{a}}$ e $4^{\mathrm{a}}$ séries. Nessa nova organização, o Regimento Escolar prevê a organização de uma Classe de Apoio para alunos com dificuldades de aprendizagem e omite-se em relação à preparação para o trabalho existente na proposta anterior. A educação infantil também é prevista para alunos de 0 a 5 anos, em contraposição à legislação da época, a qual previa que essa etapa deveria ser oferecida para alunos de 0 a 6 anos de idade.

A organização da educação infantil na forma de atendimento a crianças de 0 a 5 anos de idade e do ensino fundamental em dois ciclos foi a estratégia lançada pelo governo municipal no ano de 2001, quando houve uma redução da primeira etapa da educação básica e a consequente ampliação do ensino fundamental em todas as escolas municipais, através do "Projeto de Implantação dos Ciclos de Aprendizagem", o qual tinha a finalidade explícita de "romper com a cultura da repetência" existente na prática da educação municipal, instituindo, a partir de então, a "pedagogia do sucesso". (PONTA GROSSA, 2001). Essa proposta estava, portanto, sendo implantada em todas as escolas municipais e não apenas na escola para surdos. A análise do Regimento Escolar do ano de 2002 indica que a proposta inicial de educação para surdos foi sendo, aos poucos, absorvida pela organização mais ampla das escolas regulares do município. A proposta de uma educação específica para a comunidade surda ficou subordinada à organização mais geral das escolas regulares da rede municipal, demonstrando a força dos agentes políticos na determinação político-pedagógica interna das escolas.

Contraditoriamente ao encaminhamento dado pelo órgão central da educação do município, e demonstrando um resquício de autonomia, a Proposta Pedagógica (2002) justifica a necessidade de um trabalho educacional diferenciado com alunos surdos:

Sendo assim, o Projeto aqui apresentado justifica-se pela necessidade de ter uma filosofia de trabalho bem definida, uma Política educacional Bilíngüe-Multicultural (Língua Brasileira de Sinais e Língua Portuguesa) reconhecendo a educação de surdos com traços diferenciados, descaracterizando a prática do modelo terapêutico da surdez, possibilitando a construção de uma identidade surda saudável. (PROPOSTA PEDAGÓGICA, 2002, p. 5).

No entanto, mesmo tendo uma proposta pedagógica diferenciada, que apresentava algumas possibilidades de trabalho alternativo e voltado às necessidades de alunos surdos, a organização pedagógica interna da instituição de ensino esteve vinculada às orientações gerais do ensino regular no âmbito municipal. Essa questão pode ser uma justificativa para os resultados obtidos no período em que a escola esteve em funcionamento. No limite das dificuldades administrativas, financeiras e pedagógicas para o funcionamento de qualquer estabelecimento público de ensino, os resultados obtidos estiveram muito aquém daquele esperado de uma proposta em busca de melhores oportunidades educacionais para uma comunidade tão marginalizada socialmente como a comunidade surda, conforme dados obtidos sobre os resultados de aprendizagem dos alunos atendidos. 


\section{Elementos que justificaram a cessação das atividades}

No limite da implantação de uma proposta pedagógica que respeitasse o processo educacional de pessoas surdas, a organização interna da escola esteve subordinada às orientações mais amplas do Sistema Municipal de Ensino, afetas também às escolas regulares.

Considerando que na organização existente nas escolas municipais no período pesquisado havia a progressão continuada dentro dos ciclos, ocorrendo a possibilidade de reprovação ao final de cada ciclo caso o aluno não atingisse os objetivos curriculares mínimos para a etapa respectiva, os resultados obtidos pela Escola de Surdos demonstram, no mínimo, um limite no encaminhamento externo (político) e interno (pedagógico) referente à proposta de uma educação para pessoas surdas.

As tabelas 1 e 2 demonstram os resultados sobre o desempenho dos alunos no período em que a Escola para Surdos esteve em funcionamento.

A reprovação de $100 \%$ dos alunos ao final do $1^{\mathrm{o}}$ ciclo, nos anos de 2002, 2004 e 2008, reforça o limite nos encaminhamentos externos e internos, visto que o número de alunos surdos atendidos foi mínimo. No $2^{\circ}$ ciclo, os resultados, embora um pouco melhores em relação ao $1^{\circ}$ ciclo, ainda não se mostraram satisfatórios em seu conjunto, pois apenas nos anos de 2003, 2006 e 2007 houve aprovação dos alunos acima do percentual de $60 \%$.

Tabela 1 - Resultados ao final do $1^{\circ}$ ciclo - 2002 - 2008

\begin{tabular}{|c|c|c|c|c|}
\hline Ano & Total de alunos & Aprovados & Reprovados & Transferidos \\
\hline 2002 & 02 & $\begin{array}{c}0 \\
0 \%\end{array}$ & $\begin{array}{c}02 \\
100 \%\end{array}$ & - \\
\hline 2003 & 03 & $\begin{array}{c}03 \\
100 \% \\
\end{array}$ & $\begin{array}{c}0 \\
0 \% \\
\end{array}$ & - \\
\hline 2004 & 02 & $\begin{array}{c}0 \\
0 \%\end{array}$ & $\begin{array}{c}02 \\
100 \%\end{array}$ & - \\
\hline 2005 & 05 & $\begin{array}{c}03 \\
60 \% \\
\end{array}$ & $\begin{array}{c}02 \\
40 \% \\
\end{array}$ & - \\
\hline 2006 & 06 & $\begin{array}{c}05 \\
83 \%\end{array}$ & $\begin{array}{c}01 \\
17 \%\end{array}$ & - \\
\hline 2007 & 06 & $\begin{array}{c}04 \\
67 \%\end{array}$ & $\begin{array}{c}02 \\
33 \%\end{array}$ & - \\
\hline 2008 & 04 & $\begin{array}{c}0 \\
0 \%\end{array}$ & $\begin{array}{c}04 \\
100 \%\end{array}$ & - \\
\hline
\end{tabular}

Fonte: Relatórios Finais do Estabelecimento - 2002 - 2008

Tabela 2 - Resultados ao final do $2^{\circ}$ ciclo - 2002-2008

\begin{tabular}{|c|c|c|c|c|}
\hline Ano & Total de alunos & Aprovados & Reprovados & Transferidos \\
\hline 2002* & - & - & - & - \\
\hline 2003 & 16 & $\begin{array}{c}12 \\
75 \%\end{array}$ & $\begin{array}{c}04 \\
25 \%\end{array}$ & - \\
\hline 2004 & 08 & $\begin{array}{c}03 \\
38 \%\end{array}$ & $\begin{array}{c}05 \\
62 \%\end{array}$ & - \\
\hline 2005 & 15 & $\begin{array}{c}04 \\
27 \% \\
\end{array}$ & $\begin{array}{c}10 \\
67 \% \\
\end{array}$ & $\begin{array}{l}01 \\
6 \% \\
\end{array}$ \\
\hline 2006 & 10 & $\begin{array}{c}10 \\
100 \%\end{array}$ & $\begin{array}{c}0 \\
0 \%\end{array}$ & - \\
\hline 2007 & 05 & $\begin{array}{c}03 \\
60 \% \\
\end{array}$ & $\begin{array}{c}02 \\
40 \% \\
\end{array}$ & - \\
\hline 2008 & 05 & $\begin{array}{c}0 \\
0 \%\end{array}$ & $\begin{array}{c}02 \\
40 \%\end{array}$ & $\begin{array}{c}03 \\
60 \%\end{array}$ \\
\hline
\end{tabular}

Fonte: Relatórios Finais do Estabelecimento - 2002 - 2008

${ }^{*}$ No ano de 2002 não houve a oferta do $2^{\circ}$ ano do $2^{\circ}$ ciclo ou classe equivalente. 
Os resultados obtidos no período parecem ter sido um dos fatores determinantes para justificar a cessação das atividades escolares pela instituição. Somam-se a essa questão a política de inclusão de alunos com deficiência no ensino regular, ocorrida com maior ênfase a partir do ano de 2005. A política de inclusão esteve atrelada às propostas do governo federal, através das quais houve maior preocupação em incluir alunos no ensino regular, a cessação de classes especiais e a implantação de salas de recursos multifuncionais. Não há, neste texto, o objetivo de apresentar as implicações de ordem pedagógica e organizacional dessa adesão às propostas do governo federal.

A justificativa dada pela Secretaria Municipal de Educação para a cessação das atividades escolares da Escola para Surdos corrobora o posicionamento de vinculação à proposta de inclusão de alunos com deficiência no ensino regular.

A inclusão das crianças com necessidades especiais (área auditiva/surdez) em classes do ensino público municipal (Educação Básica: Educação Infantil, Ensino Fundamental), conforme legislação vigente descaracterizando-se, desta forma, o atendimento especializado para a qual a Escola foi criada, visto que constava em sua denominação o atendimento específico: "Para Surdos".

Em consequência, a inclusão destes alunos no ensino público municipal foi ocorrendo a diminuição de matrículas com a cessação gradativa, principalmente no último ano letivo/2008, do(s) ano(s)/ciclo(s), ali ofertados. (PONTA GROSSA, 2009, p. 2)

Ainda, o Conselho Municipal de Educação, ao analisar a solicitação de cessação das atividades escolares, considerou que "os alunos foram encaminhados para outros estabelecimentos de ensino, dando prosseguimento aos estudos, tanto no Ensino Fundamental como Educação Infantil" (PONTA GROSSA, 2009, p. 53), não havendo considerações específicas quanto ao tratamento pedagógico sobre a educação de pessoas surdas ou análise mais detalhada sobre os encaminhamentos pedagógicos passados e futuros dos alunos envolvidos.

Esse posicionamento do órgão normativo do sistema municipal, que é corresponsável pelo direcionamento político-educacional em análise, demonstra como a adesão às propostas governamentais pode determinar a oferta da educação na realidade concreta.
Dessa forma, as atividades escolares da Escola para Surdos foram cessadas definitivamente através da Resolução n ${ }^{\circ}$ 001/09, publicada em 22 de julho de 2009.

\section{Considerações finais}

A proposta educativa diferenciada de atendimento de alunos surdos, criada em 2001 e autorizada em 2002, mostrou um compromisso com as necessidades da comunidade surda e, portanto, pode ser considerada como um avanço em relação à realidade educacional como um todo.

No entanto, é preciso considerar que sua implantação demonstrou fragilidade frente aos interesses governamentais do período, sendo subsumida pela organização geral da oferta da educação municipal, quando houve sua reorganização através da substituição da oferta da educação seriada para a organização em ciclos de aprendizagem. A subordinação à organização das demais escolas municipais de ensino regular colaborou para o enfraquecimento da proposta inicial de atendimento aos alunos surdos e, consequentemente, para o esvaziamento tanto da proposta pedagógica quanto da procura das famílias pela Escola para Surdos. Esses fatos podem ser apontados como possíveis limites aos quais a Escola para Surdos esteve atrelada no período de seu funcionamento.

O projeto de pesquisa que deu origem ao presente relato ainda está em desenvolvimento. Portanto, os dados apresentados são parciais e apontam para a necessidade de maior aprofundamento teórico sobre as questões levantadas e análise do impacto do processo de inclusão dos alunos surdos no ensino regular, além da forma de encaminhamento pedagógico que vem sendo dispensado a eles.

O debate sobre a questão do ensino de alunos surdos não se findou com a cessação das atividades escolares no estabelecimento especializado, pois os alunos foram inseridos em escolas de ensino regular. A questão da inclusão desses alunos nas escolas regulares ainda carece de maiores estudos e pesquisas, pois o acompanhamento e o impacto social e pedagógico da política de educação inclusiva são incipientes no contexto municipal pesquisado, não sendo possível apontar resultados amplos e científicos sobre a medida. 
Todavia, não se pode desconsiderar que os alunos egressos da escola para surdos que foram inseridos na escola regular são cidadãos reais e, independentemente de estarem em escola especial ou regular, seu direito à educação precisa ser não apenas assegurado em termos legais e normativos, mas garantido efetivamente pelos órgãos públicos responsáveis, através de ações pedagógico-administrativas que possibilitem tal garantia. É aí que reside o grande desafio para além da simples existência ou não de estabelecimentos em funcionamento, pois nesses estabelecimentos cidadãos precisam ter seus direitos efetivamente garantidos.

\section{Referências}

BRASIL. Decreto 5.626/05. Regulamenta o ensino de LIBRAS.

LODI, A. C. B. Plurilinguismo e surdez: uma leitura bakhtiniana da história da educação dos surdos. Educação e Pesquisa, São Paulo, v. 31, n. 3, p. 409-424, set./dez. 2005.

PARANÁ. SEED. CEF. Parecer 241/2003. Alteração de Denominação. Curitiba, 26/03/2003.

PONTA GROSSA. SME. Projeto de Implantação dos ciclos de aprendizagem. Ponta Grossa, 2001.

PONTA GROSSA. SME. CME. Processo de cessação da escola municipal para surdos professora Elisete Delgobo: Educação Infantil e Ensino Fundamental, 2009.

PROPOSTA PEDAGÓGICA. Escola municipal para surdos "Geny de Jesus Souza Ribas": Educação Infantil e Ensino Fundamental. Ponta Grossa. 2002.

REGIMENTO ESCOLAR. Escola Municipal para surdos "Geny de Jesus Souza Ribas": Educação Infantil e Ensino Fundamental. Ponta Grossa. 2001.

Escola Municipal para surdos "Geny de Jesus Souza Ribas": Educação Infantil e Ensino Fundamental. Ponta Grossa. 2002.

SANTANA A. P.; BERGAMO, A. Cultura e identidade surdas: encruzilhada de lutas sociais e teóricas. Educ. Soc., Campinas, v.26, n.91, p.565-582, maio/ago. 2005.

\section{Agradecimentos:}

À Secretaria Municipal de Educação de Ponta Grossa pela disponibilização dos dados referentes à criação, autorização, prorrogação e cessação de atividades escolares necessários ao desenvolvimento do Projeto de Pesquisa em andamento intitulado "Escolas Municipais em Ponta Grossa: determinantes na criação, existência político-pedagógica e cessação de atividades escolares".

Data de submissão:12/05/2012

Data de aceite: 18/09/2012 